\title{
Do smoke-free laws affect revenues in pubs and restaurants?
}

\author{
Hans Olav Melberg · Karl E. Lund
}

Received: 22 January 2010/ Accepted: 2 November 2010/Published online: 20 November 2010

(C) The Author(s) 2010. This article is published with open access at Springerlink.com

\begin{abstract}
In the debate about laws regulating smoking in restaurants and pubs, there has been some controversy as to whether smoke-free laws would reduce revenues in the hospitality industry. Norway presents an interesting case for three reasons. First, it was among the first countries to implement smoke-free laws, so it is possible to assess the long-term effects. Second, it has a cold climate so if there is a negative effect on revenue one would expect to find it in Norway. Third, the data from Norway are detailed enough to distinguish between revenue from pubs and restaurants. Autoregressive integrated moving average (ARIMA) intervention analysis of bi-monthly observations of revenues in restaurants and pubs show that the law did not have a statistically significant long-term effect on revenue in restaurants or on restaurant revenue as a share of personal consumption. Similar analysis for pubs shows that there was no significant long-run effect on pub revenue.
\end{abstract}

Keywords Restaurant revenue - ARIMA · Norway · Smoke-free laws

JEL Classification I18

H. O. Melberg ( $₫)$

Health Economics Research Programme at the University of Oslo, Institute of Health Management and Health Economics, P.O. Box 1089, Blindern, 0317 Oslo, Norway

e-mail: hans.melberg@gmail.com

K. E. Lund

Norwegian Institute for Alcohol and Drug Research, PO Box 565, Sentrum, 0105 Oslo, Norway

e-mail: kel@ sirus.no

\section{Introduction}

In many countries, the propagation of smoke-free air policies has been slowed by fears that restrictions on smoking may have a negative impact on businesses [1]. The most vigorous debate has revolved around the business activity of pubs and restaurants [2]. Debates centre on the claim that there will be a loss of revenue as a result of smokers visiting these establishments less frequently, cutting their visits shorter and spending less money than they otherwise would if smoking were permitted. Against this, it is argued that the premise that smokers would change their habits is wrong or that even if some smokers reduce their visits, it could be balanced by non-smokers increasing their visits. An extensive and growing body of literature on the economic impact of smoke-free policies in the hospitality sector shows that smoke-free air policies have no economic impact on restaurants, pubs and other segments of the hospitality industry [3, 4], with the possible exception of gaming establishments [5, 6]. However, most of this research has been conducted in regions of the world with a climate less hostile to outdoor smoking than the cold and wet Norwegian climate. In addition, many studies have also been limited to a short time period after the law was introduced, and few studies have had the data to compare and analyse the effects for restaurants and bars separately. This article contributes to the existing literature by examining the long-term effects of the law on smoke-free environments separately on the revenues of pubs and restaurants in a geographical region with a cold climate.

The smoke-free law came into effect on 1 June 2004. The results from a comprehensive evaluation show that the introduction of the smoke-free law was followed by a reduction in airborne nicotine and total dust in pubs and restaurants, and a decline in urinary cotinine levels in 
non-smoking hospitality workers [7]. Service workers were also observed to have increased lung function [8], a decline in respiratory symptoms [9] and better self-reported respiratory health [10]. Hospitality workers found a total ban easier to enforce than the previous partial ban and patrons reported better air quality, increased well-being and high and increasing-especially among smokers-support for the law [11]. Population-based consumer surveys showed no significant changes in the frequency of pub/bar and restaurant visits following the implementation of the law [12].

However, until now, no methodologically sound study has been conducted in Norway using valid, reliable measures of business activity covering the period before and after the implementation in order to separate the economic impact of the law from underlying economic trends and to allow sufficient time for businesses, smokers and nonsmokers to adapt their behaviour to the policy. With half of the country situated north of the Arctic Circle and the remaining parts also regularly exposed to cold winters and rainy summers, Norwegian smokers might be expected to be more affected by a law against indoor smoking than smokers living in more temperate climes. Business owners and hospitality associations therefore expressed concern when advocates of the law extrapolated evidence from research conducted in the USA and Australia and applied it to Norway. With 36\% regular smokers (27\% daily and 9\% occasionally) at the time of implementation, Norway also had higher prevalence of smokers than most countries with such policies. We therefore hypothesised that the smokefree law would have a larger economic impact in Norway compared to the lack of impact reported in the scientific literature on the topic.

\section{Methods}

\section{Design}

To examine the effect of the smoke-free law, we modelled trends in restaurant and bar revenue using a seasonally adjusted and extended ARIMA model with a dummy variable for the law. This model has been used previously in the literature to examine the effect of eliminating smoking from indoor restaurants, for instance by Stolzenberg and D'Alessio [13]. We extent this model in the sense that we include temperature as a variable, while the standard ARIMA approach only includes past values of a time series and its disturbances to predict its current value. This extension is sometimes called the ARMAX model. By differencing the data (examining changes from time period to time period as opposed to absolute levels) and including lagged variables, the model reduces the statistical problem of trends and time dependencies that exist in time-series data.

Revenues in restaurants and pubs could change for many reasons: higher income, increased population and price changes. Many of these factors could be controlled for by including them in the model, but there is always the problem of leaving out potentially important variables. To reduce the problem of omitted variables, we focused on the ratio of revenues to private consumption defined as total annual private household expenditure on goods and services. This ratio should go up or down if the smoke-free law had an effect on revenue, but it should not change in response to variables believed to have the same influence on revenue in restaurants/pubs and private consumption. By focusing on the ratio, we eliminated the need to include variables that are common to both series [14].

However, the method above does not adjust for variables that could have a disproportionate influence on revenue in restaurants and pubs compared with revenue in other sectors. For instance, above average temperatures could lead to changes in the number of restaurant and pub visits and the consumption of alcohol, which in turn affects restaurant revenue, and this should to be taken into account before assessing the impact of the law. For this reason, our model is an extended version of ARIMA in which temperature is allowed as an independent variable in addition to past values of the time series itself. This is an important variable since the summer in which the law was introduced was colder than normal. Failing to correct for temperature would mean that the dummy for the law might include the impact of the cold weather.

We use seasonal differencing to correct for the temporal pattern in restaurant and pub revenues. This implies that we are comparing changes for the same time period in different years. To test the robustness of the results, we also report the results of some alternative specifications. This includes tests without temperature, including disposable income in the model, using different lag specifications, distinguishing between short-run and long-run effects as well as focusing on the revenues directly as opposed to the ratio of revenue to personal consumption.

\section{Data}

The data on revenue from pubs, restaurants, disposable income and private household consumption were obtained from Statistics Norway, which calculates the revenues based on information from the tax authorities which, in turn, receive value added tax (VAT) reports from the hospitality units. Practically all restaurants and pubs are required to report VAT information. For the restaurants, the data consists of bi-monthly observations beginning in January 1999 and ending in August 2007. The data on 
revenue in pubs ended on the same date, but began in 2002, as this was the first year for which pub revenue was singled out in the national accounts. The data on private household consumption, personal disposable income, restaurant and pub revenue from Statistics Norway are adjusted for changes in the price level using Statistics Norways consumer price index (CPI, base year, 1998. The variables and detailed information are available from http://www.ssb.no/ english/).

Information on the average bi-monthly temperature in Oslo was collected from the Norwegian Meteorological Institute. The weather in Oslo is an indicator for the weather of the most densely populated areas of Norway, where most hospitality venues are situated.

As mentioned, the law on smoking in pubs and restaurants was introduced on the first of June 2004, and the dummy variable for the smoke-free law was assigned a value of 1 for the period after the law was introduced. Since the law was implemented in the middle of a bi-monthly period, May-June 2004 was assigned a value of 0.5.

\section{Results}

Figure 1 shows restaurant revenue before and after the law in 2004 (see Fig. 1). Price adjusted restaurant revenue in 2005 was $2.5 \%$ higher than in 2003 , but as a percentage of personal consumption, it went down from 1.65 to $1.57 \%$. The same pattern was true for revenue in bars and pubs. In 2005 , the year after the law, pub revenue was $1.2 \%$ higher than the year before (2003). Although revenue increased, it did not increase as much as personal consumption in general, so as a share of consumption, pub revenue went down from 0.077 to $0.071 \%$.

Figure 1 also reveals that there is a strong seasonal trend in restaurant revenue and that seasonal differencing eliminated the temporal pattern. The autocorrelation diagram of the seasonally differenced data was wave shaped, while the partial autocorrelation showed a significant spike at the first lag. This suggested that a seasonally differenced ARIMA model with one seasonal and two autoregressive terms was a good starting point for testing the effects of the law [15]. Further testing using the Akaike's Information Criterion also indicated that including a seasonally autoregressive term improved the fit. The residuals in this model-ARIMA $(2,0,0)(1,1,0)_{6}$ - showed no remaining significant autocorrelation with a Ljung-Box $\mathrm{Q}(12)$ statistics of 9.2 $(p=0.69)$. Using this trend structure, the analysis reported a statistically insignificant effect of the law (See Table 1). To interpret the coefficients, it is helpful to recall that the dependent variable is not restaurant revenue directly, but the change in restaurant revenue as measured by its share of personal consumption. Since this is a small number in itself, and the change from time period to time period is even smaller, one would expect the coefficient to be quite small.

The ratios of revenue in pubs to overall personal consumption also had a seasonal component, but with a different autocorrelation and partial autocorrelation structure compared with restaurant revenue. The average autocorrelation decayed exponentially, and the partial autocorrelation had a spike at lag 1 . This indicated that a seasonally differenced ARIMA model with one autoregressive
Fig. 1 Restaurant revenue in Norway, 1999-2007 (overall, as a share of personal consumption and seasonally differenced)

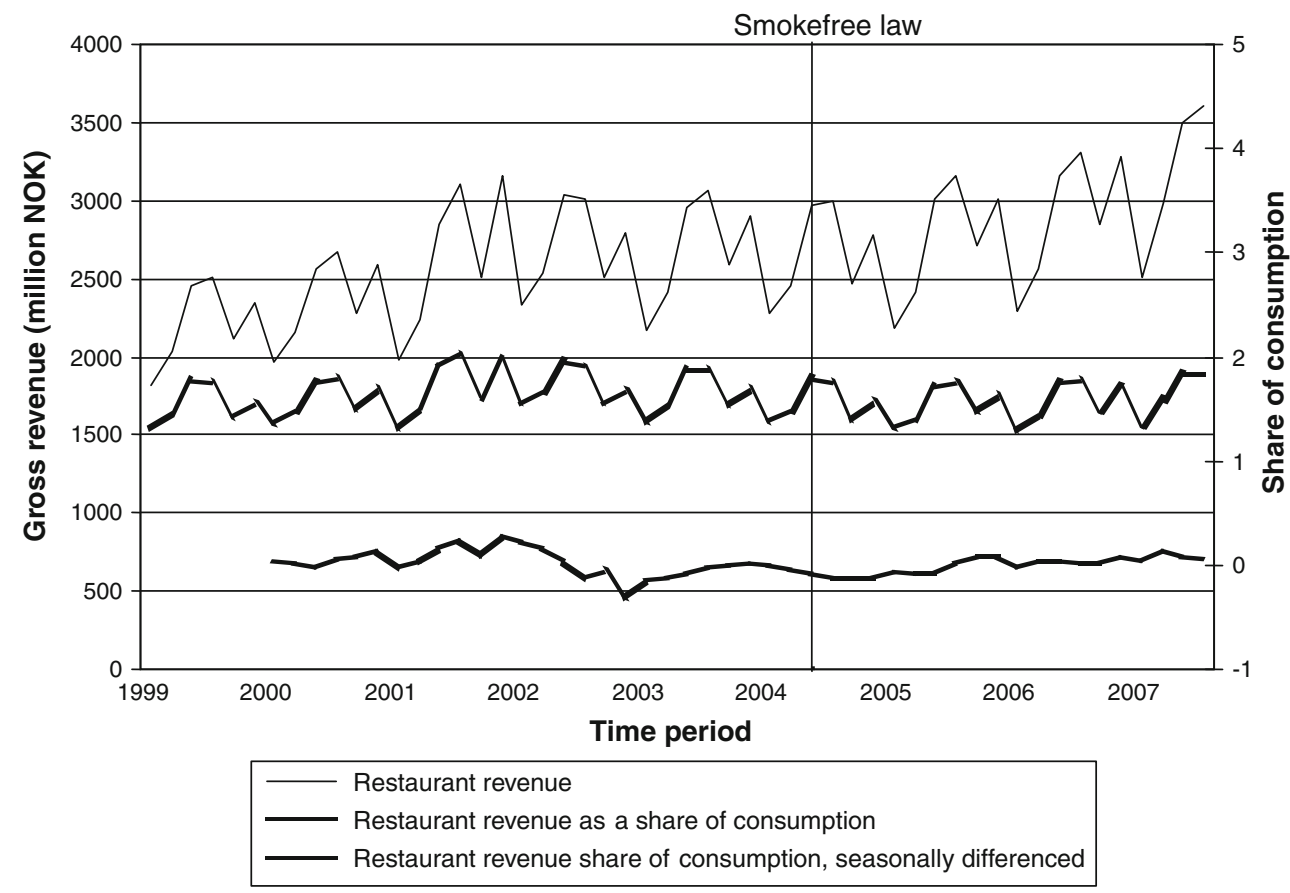


parameter would be a good fit. The diagnostic tests confirmed that this model-ARIMA $(1,0,0)(0,1,0)_{6}$ - passed the standard tests. The Ljung-Box Q(12) statistic was 10.73 $(p=0.55)$, which implies that no additional lags were needed to remove the time trend between the observations. In this model, the dummy for the law on smoking was negative and statistically significant at the $1 \%$ level (see Table 2; Fig. 2).

Table 1 Results of ARIMA analysis of the effects of the smoke-free law on the ratio of restaurant revenue to overall personal consumption

\begin{tabular}{lccr}
\hline Variable & Coefficient & $95 \%$ CI & \\
\hline Smoke-free law & -0.062 & -0.401 & -0.278 \\
Temperature & 0.011 & -0.001 & 0.022 \\
Constant & 0.019 & -0.079 & 0.117 \\
Autoregressive terms & & & \\
$\quad$ Lag1 & 0.431 & -0.117 & 0.979 \\
$\quad$ Lag2 & 0.380 & 0.112 & 0.648 \\
Seasonally autoregressive term & & \\
$\quad$ Lag1 & -0.379 & -0.703 & -0.054 \\
\hline
\end{tabular}

Table 2 Results of ARIMA analysis of the effects of the smoke-free law on the ratio of pub revenue to overall personal consumption

\begin{tabular}{lrrr}
\hline Variable & Coefficient & $95 \%$ CI & \\
\hline Smoke-free law & -0.0089 & -0.0137 & -0.0042 \\
Temperature & 0.0006 & -0.0137 & 0.0013 \\
Constant & 0.0013 & -0.0016 & 0.0041 \\
Autoregressive term & & & \\
$\quad$ Lag1 & 0.2545 & -0.3070 & 0.8160 \\
\hline
\end{tabular}

Further tests were carried out to examine the robustness of these results (see Table 3). The constant was removed to see whether underlying trends affected the results. This did not change the statistical significance of any of the results and only moderately reduced the magnitude of the estimated effect of the law. Next, bi-monthly dummies were added to the model to examine whether results were affected by systematic temporal patterns not captured by the seasonal model. None of these dummies were significant, and adding them had no significant effect on the coefficients and no effect on the statistical significance. The same is true when we add moving average terms, remove temperature and included disposable income in the model. In all of these models, the effect of the law was never statistically significant for restaurant revenue, but always statistically significant at the 5\% level for pub revenue.

To distinguish between short- and long-run effects, we used a model in which the effect of the law was captured by two dummies: one within the first year after the introduction of the law (the short run) and one after that (the long run). In these models, the law had no statistically significant effect on either restaurant or pub revenue as a share of personal consumption in the long run.

When we use revenues alone as the dependent variable as opposed to revenue as a share of personal consumption, the law had no statistically significant effect on restaurant revenue and pub revenue. Further tests on the model with pub revenue as the dependent variable also confirmed this. Adding and subtracting autoregressive and moving average terms did not change the statistical insignificance of the law in these models.
Fig. 2 Pub revenue in Norway, 1999-2007 (overall, as a share of personal consumption and seasonally differenced)

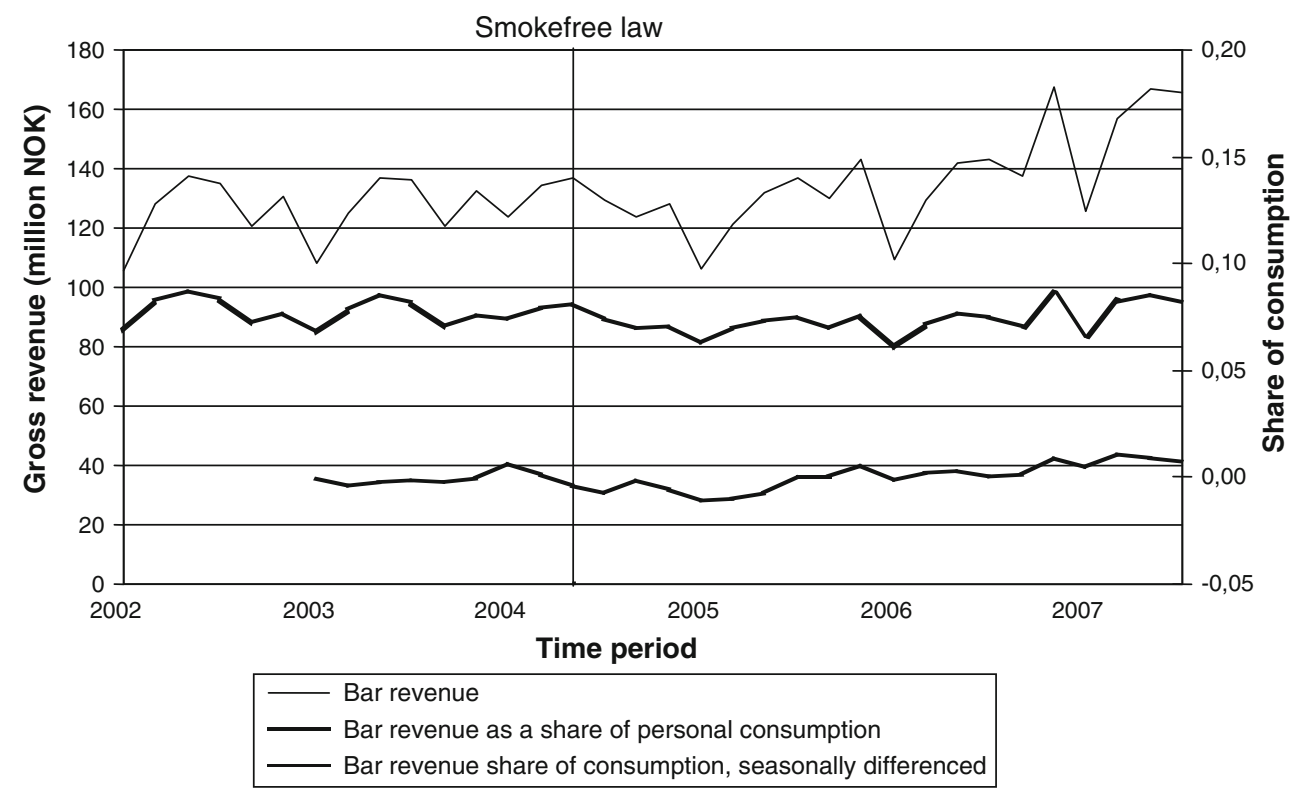


Table 3 Results from different models
* Significant at the $1 \%$ level, ** Significant at the $5 \%$ level

\begin{tabular}{lccc}
\hline Model & $\begin{array}{l}\text { Coefficient on smoking } \\
\text { law dummy }\end{array}$ & $\begin{array}{l}\text { Standard } \\
\text { error }\end{array}$ & $\begin{array}{l}\text { Akaike's Information } \\
\text { Criterion (AIC) }\end{array}$ \\
\hline Restaurant revenue & & & \\
Benchmark & -0.062 & 0.173 & -101 \\
Removing the constant term & -0.054 & 0.177 & -100 \\
Adding seasonal dummies & -0.060 & 0.171 & -92 \\
Adding moving average term & -0.060 & 0.164 & -99 \\
Removing temperature & -0.085 & 0.233 & -105 \\
Including income & -0.022 & 0.094 & -87 \\
Two effect dummies & & & \\
$\quad$ Short-run effect & -0.050 & 0.184 & -107 \\
Long-run effect & 0.004 & 0.254 & \\
Revenue as the dep. variable & -146 & 183 & 1840 \\
Pub revenue & & & -216 \\
Benchmark & $-0.0089^{*}$ & 0.0024 & -214 \\
Removing the constant term & $-0.0076^{*}$ & 0.0023 & -208 \\
Adding seasonal dummies & $-0.0090^{*}$ & 0.0032 & -214 \\
Adding moving average term & $-0.0090^{*}$ & 0.0025 & -233 \\
Removing temperature & $-0.0099^{*}$ & 0.0033 & -216 \\
Including income & $-0.0081^{*}$ & 0.0020 & \\
Two effect dummies & $-0.0093^{* *}$ & 0.0037 & -229 \\
Short-run effect & -0.0082 & 0.0059 & \\
Long-run effect & -18 & 10 & \\
Revenue as the dep. variable & & & \\
\hline & & & \\
\hline
\end{tabular}

\section{Discussion}

Many previous studies have reported that introducing smoke-free laws does not have a significant economic impact (positive or negative) on the hospitality industry. This study reinforces and refines this conclusion in three novel ways. First of all, many studies have not had access to data over a long-time period after the law on smoking was introduced. This leaves the studies open to the charge that they have failed to find the long-term effects because the time period or number of observations after the law was introduced was too small or because the public had not yet adjusted to the new laws. In contrast, this study uses a long time series with data for several years after the introduction of the law.

Second, the results show that there was no significant result on revenue in restaurants. The results for pubs were more mixed. As a share of personal consumption revenues in pubs went down in the short run, but in the long-run and in absolute terms revenues increased. The differences between restaurants and pubs could be partially explained by the fact that Norwegian smokers have been found to patronise pubs more frequently than non-smokers, while the same variations have not been observed in their patronage of restaurants [12]. One might argue that an influx of non-smokers to smoke-free pubs could make up for the partial loss of smokers [16]. This would certainly be true to some extent - and real pub revenues did go up after 1 year-but the numbers also suggest that this influx was not large enough to make pub revenues grow as a share of overall-smoker and non-smoker-personal consumption.

The distinction between pub and restaurant revenue means that the results do not contradict previous results using the same methodology. For instance, Luk et al. [14] showed that the law on smoking did not have an effect on revenue, but this was for the hospitality industry as a whole since "bar and licensed restaurant sales could not be analysed separately." Analysis on bar revenues in the United States has also showed no statistically significant effects of smoke-free laws for bars [17, 18].

Because annual restaurant revenues are almost 20 times larger than pub revenues in Norway, the results for the restaurants are most important for the industry as a whole. Hence, our results are in agreement with Luk et al. [14], but it extends the analysis by examining a sub-sector in which the law may have had a statistically significant effect. As for the economic importance of this, the size of the coefficient is relatively small, but not insignificant. The direct effect of the smoke-free law, given the size of the coefficient, can be found by calculating the predicted level of pub revenue as a share of personal consumption before and after the law. The overall share of pub revenue out of all 
personal consumption before the law was 0.077 in 2003, and the size of the coefficient implies that this share would be between 0.063 and 0.073 after the law i.e. a reduction between 5 and $18 \%$ in pub revenue's share of total personal consumption. The actual change between 2003 and 2005 was a reduction of $8 \%$.

Third, the results indicate that it may be important to correct for other variables, such as temperature. This variable was not significant at the 5\% level, but it was significant at the $10 \%$ level. The coefficients in the models without temperature showed that the model without temperature exaggerated the effect of the law. Since the law was introduced during an unusually cold summer, one would expect below average revenues, and this change should not be confused with the effects of the law. Previous research has mainly been conducted in areas with a more temperate climate. Cold climate could affect revenue negatively in the sense that smokers would refrain from visiting pubs and restaurants as they have to step outside to smoke. However, it should be noted that many restaurants adapted to the new legislation by providing blankets, heaters and shelters for smokers. This may explain why the coefficient for temperature was only significant at the $10 \%$ level.

There are some limitations to the study. First, because pub revenue was not recorded as a separate category until after 2001, there are fewer observations behind the results for pub revenue than restaurant revenue, which starts in 1999. This raises the danger of over-fitting and sensitivity to model specification. However, the analysis shows that the results were stable despite different specifications.

One might also argue that the result for the restaurants may be economically important even if it is not statistically significant. Statistical tests have an inbuilt asymmetry that makes it hard to reject the null hypothesis that there is no effect on revenue [19]. While this is true, the results show that the variable was not even close to being statistically significant for restaurant revenues.

The statistical analysis focuses on the long-run overall effect of the law on smoking. This long-run effect may be composed of effects of varying strength in the short and long run. The data on revenues show that there was little, if any, immediate or long-term impact on restaurant revenue since this grew more in 2005 (3.3\%) than in any of the three previous years. Pub revenue is more interesting since it declined by $1 \%$ in 2005 and increased by a record $7.8 \%$ in 2006. This suggests that there was some short-run impact and then a readjustment towards a more natural level. It also suggests that the statistical analysis of revenue alone is correct in finding no long-term effect of the law, since the short-term negative change was balanced by a positive change the next year.
The difference between the short and the long run suggested by the data was also observed in the statistical analysis. When the effect was split between a short-run and a long-run dummy variable, the smoke-free law did not decrease revenues as a share of personal consumption in the long run. This supports the argument that the effect on pub revenue as a share of consumption is mainly composed of a short-run effect (within the first year) and in the long run the effect is no longer significant.

\section{Conclusion}

Our results indicate that smoke-free laws do not affect restaurant revenue directly or as a share of private consumption even in a country known for its harsh climate. There is some evidence for a short-run effect on pub revenue as a share of private consumption, but there is no evidence of a short-run effect on the absolute level of pub revenue and no evidence for a long-run effect using either measure.

Acknowledgments We thank Statistics Norway for making the data available.

Open Access This article is distributed under the terms of the Creative Commons Attribution Noncommercial License which permits any noncommercial use, distribution, and reproduction in any medium, provided the original author(s) and source are credited.

\section{References}

1. Dearlove, J.V., Bialous, S.A., Glantz, S.A.: Tobacco industry manipulation of the hospitality industry to maintain smoking in public places. Tob. Control 11(2), 94-104 (2002)

2. Eriksen, M., Chaloupka, F.: The economic impact of clean indoor air laws. CA Cancer J. Clin. 57(6), 367-378 (2007)

3. International Agency for Research on Cancer: IARC handbooks of cancer prevention: Tobacco control, vol. 13. Evaluating the effectiveness of smoke-free policies. International Agency for Research on Cancer, Lyon, France (2009)

4. Scollo, M., Lal, A., Hyland, A., Glantz, S.: Review of the quality of studies on the economic effects of smoke-free policies on the hospitality industry. Tob. Control 12(1), 13-20 (2003)

5. Lal, A., Siahpush, M.: The effect of smoke-free policies on electronic gaming machine expenditure in Victoria, Australia. J. Epidemiol. Community Health 62(1), 11-15 (2008)

6. Mandel, L.L., Alamar, B.C., Glantz, S.A.: Smoke-free law did not affect revenue from gaming in Delaware. Tob. Control 14(1), 10-12 (2005)

7. Ellingsen, D.G., Fladseth, G., Daae, H.L., Gjolstad, M., Kjaerheim, K., et al.: Airborne exposure and biological monitoring of bar and restaurant workers before and after the introduction of a smoking ban. J. Environ. Monit. 8(3), 362-368 (2006)

8. Skogstad, M., Kjaerheim, K., Fladseth, G., Gjolstad, M., Daae, H.L., et al.: Cross shift changes in lung function among bar and restaurant workers before and after implementation of a smoking ban. Occup. Environ. Med. 63(7), 482-487 (2006) 
9. Eagen, T.M., Hetland, J., Aaro, L.E.: Decline in respiratory symptoms in service workers five months after a public smoking ban. Tob. Control 15(3), 242-246 (2006)

10. Hetland J., Aarø L.E.: Smokefree restaurants and pubs: air quality, self reported health and job satisfaction. SIRUS Report 4/2005. Oslo: Norwegian Institute for Alcohol and Drug Research (2005)

11. Lund, K.E., Lund, M.: The impact of smoke-free hospitality venues in Norway. Eurohealth 12(4), 22-24 (2007)

12. Lund K.E.: The introduction of smoke-free hospitality venues in Norway. Impact on revenues, frequency of patronage, satisfaction and compliance. SIRUS Report 2/2006. Oslo: Norwegian Institute for Alcohol and Drug Research (2006)

13. Stolzenberg, L., D'Alessio, S.J.: Is nonsmoking dangerous to the health of restaurants? The effect of California's indoor smoking ban on restaurant revenues. Eval. Rev. 31(1), 75-92 (2007)
14. Luk, R., Ferrence, R., Gmel, G.: The economic impact of smokefree bylaw on restaurants and bar sales in Ottawa, Canada. Addiction 101(5), 738-745 (2006)

15. Pankratz, A.: Forecasting with Univariate Box-Jenkins Models: Concepts and cases. Wiley, New York (1983)

16. Cowling, D.W., Bond, P.: Smoke-free laws and bar revenues in California-The last call. Health Econ. 14(12), 1273-1281 (2005)

17. Glantz, S.A., Smith, L.R.: The effect of ordinances requiring smoke-free restaurants and bars on revenues: A follow-up. Am. J. Public Health 87(10), 1687-1693 (1997)

18. Alamar, B., Glantz, S.A.: Effect of smoke-free laws on bar value and profits. Am. J. Public Health 97(8), 1400-1402 (2007)

19. McCloskey, D.N., Ziliak, S.T.: The standard error of regressions. J. Econ. Lit. 34(1), 97-114 (1996) 